\title{
Upward LED Lighting from the Base Suppresses Senescence of Lower Leaves and Promotes Flowering in Indoor Rose Management
}

\author{
Namiko Yamori, Yoriko Matsushima, and Wataru Yamori \\ Institute for Sustainable Agro-Ecosystem Services, The University of \\ Tokyo, Nishitokyo, Japan
}

Additional index words. bud formation, photosynthesis, supplemental lighting

\begin{abstract}
In indoor environments such as hotels, the light intensity is generally insufficient for managing plants, and flower buds often fail to open. Lamps placed above (downward lighting) take up space. We assessed the applicability of lighting from underneath (upward lighting) for the indoor management of roses. We grew plants indoors in dim light for 2 weeks under three conditions: 1) without supplemental lighting, 2) with downward light-emitting diode (LED) lighting, and 3) with LED lighting. We quantified photosynthetic components (chlorophyll and rubisco) and the maximum quantum yield of photosystem II ( $\mathrm{Fv} / \mathrm{Fm}$, an indicator of plant health) to determine the effects of each treatment on the quality and photosynthetic abilities of the leaves. We determined the ratios of dead and opened flower buds to elucidate the effects of supplemental lighting on flower bud maturation. Management without supplemental lighting decreased the number of flowers and resulted in lower-leaf senescence. Downward LED lighting promoted blooming but also resulted in lower-leaf senescence. However, upward LED lighting promoted blooming and maintained the photosynthetic abilities of the leaves, including the lower leaves. This study shows a strong case for using upward LED lighting in appropriate settings for indoor plant management and LED-based horticulture.
\end{abstract}

In hotels, shops, and other buildings, plants are often used to add color, suggest luxury, and welcome customers. In hospitals, plants are often placed in receptions and wards. Several analyses of the effects of nature and plants on human health have suggested that greenery reduces physiological stress (Chang and Chen, 2005; Coleman and Mattson, 1995; Lohr et al., 1996; Park et al., 2008; Ulrich et al., 1991). Viewing nature or plants is considered a pleasant distraction that increases positive feelings, reduces anxiety, and helps recovery from stress (Miyazaki

Received for publication 23 Feb. 2021. Accepted for publication 25 Mar. 2021.

Published online 2 June 2021.

This study was partly supported by the Japan Society for the Promotion of Science (JSPS) (KAKENHI grant numbers $16 \mathrm{H} 06552,18 \mathrm{H} 02185$, and $18 \mathrm{KK} 0170$ to W.Y.)

All authors conceived and designed the experiments. W.Y. performed the experiments. N.Y. and Y.M. analyzed the data and prepared figures and graphs. Y.M. and W.Y. prepared the manuscript. All authors contributed extensively to the finalization of the work

The authors declare that the research was conducted in the absence of any commercial or financial relationships that could be construed as a potential conflict of interest.

W.Y. is the corresponding author. E-mail: yamori@ g.ecc.u-tokyo.ac.jp.

This is an open access article distributed under the CC BY-NC-ND license (https://creativecommons. org/licenses/by-nc-nd/4.0/). et al., 2011; Park et al., 2004; Ulrich, 1992). Therefore, a comprehensive understanding of the mechanisms of flower opening and plant senescence would benefit commercial horticulture and plant science in general.

Many studies have focused on how to preserve cut flower quality because cut flowers are valued for their beauty. Therefore, most studies have focused on senescence to improve vase life (van Doorn and Woltering, 2008). Several agents, such as inhibitors of ethylene production or action (van Doorn and Woltering, 2008) and sugars (Ichimura et al., 2003; Paulin, 1979), have been developed to improve cut flower quality. In addition, the light level during cultivation affects the regulation of water loss, which is an important factor in long keeping quality (Fanourakis et al., 2013, 2019; Mortensen and Fjeld, 1998). It is also important to establish methods to control flower opening as well as senescence because the ornamental value of many plants lies in the process of blooming. Yet, there are few studies of the efficient maintenance of plants indoors, where the light intensity is low (Fanourakis et al., 2013). This highlights the need to study the effects of supplemental lighting on indoor plant management to delay senescence of leaves and promote flower opening.

Artificial lighting intensifies plant production, improves crop quality, and allows cultivation wherever natural light is not sufficient. Previously, the use of conventional light sources such as fluorescent lamps entails high electricity costs. The introduction of LEDs into plant cultivation in the 2000 s reduced the costs of both lighting and cooling because high-intensity LED lamps offer a long functional life, low energy consumption, small size, light weight, and low heat production (Hernández and Kubota, 2012; Zhang et al., 2011). In addition, the spectral distribution of LEDs can be easily controlled (Goto, 2012). Therefore, the use of LEDs as a supplemental light source enables fine control of the light environment.

Light conditions, including intensity, wavelength, and photoperiod, affect several aspects of plant physiology, including plant growth and flower opening (Currey and Lopez, 2013; Kaihara and Takimoto, 1980, 1981; Yamori et al., 2016a, 2016b; Yamori and Shikanai, 2016). Leaf senescence at low light intensity is accompanied by chlorophyll loss, degradation of photosynthetic proteins, decreased photosynthetic activity, and remobilization of nutrients to younger tissues (Brouwer et al., 2012; Gan and Amasino, 1997; Weaver and Amasino, 2001). Indoor environments with indirect lighting are generally inadequate for plant growth, and growth and flower bud maturation are generally suppressed (Corbesier et al., 1998; King et al., 2008; Sheldon et al., 2000). Therefore, the use of supplemental lighting is critical to enhancing both production and quality under low light environments. However, when plants are lit from above, the structure that supports the light source takes up space. Recent work has shown that supplemental upward lighting using LEDs could retard outer leaf senescence and increase the photosynthetic rate of lettuce, thus enhancing yield (Joshi et al., 2017; Zhang et al., 2015). With this method, the LED light source can be installed on the pot or the soil, requiring no special structure. Here, we investigated the effects of supplemental lighting from different directions on the indoor management of rose plants. We analyzed the contents of photosynthetic components and the maximum quantum yield of photosystem II $(\mathrm{Fv} / \mathrm{Fm})$ to determine the effects of each treatment on the photosynthetic characteristics of upper, middle, and lower leaves, and we determined the ratios of dead and flowering buds to elucidate the effects on flower bud maturation.

\section{Materials and Methods}

Plant materials, growth conditions, and supplemental light treatments. The 2-year-old plants of potted miniature rose (Rosa hybrida L.) grown in a mixture of peat and perlite (4:1 by volume) in 1-L pots were obtained from a commercial nursery (Rose Nakashima, Nagano, Japan) and grown until each plant had 50 to 60 flower buds. Then, the plants were moved indoors with $65 \% \pm 5 \%$ relative humidity and $25 \pm 1{ }^{\circ} \mathrm{C}$. Light at 10 to $20 \mu \mathrm{mol} \cdot \mathrm{m}^{-2} \cdot \mathrm{s}^{-1}$ at plant height was supplied for $12 \mathrm{~h} /$ day (0900-2100 HR) by fluorescent lamps located $20 \mathrm{~cm}$ above the plants to simulate the light conditions of hotel rooms and shops.

Three treatments were prepared: no supplemental lighting (control); downward lighting at $150 \mu \mathrm{mol} \cdot \mathrm{m}^{-2} \cdot \mathrm{s}^{-1}$; and upward lighting at $150 \mu \mathrm{mol} \cdot \mathrm{m}^{-2} \cdot \mathrm{s}^{-1}$ (E46 LED; MAXGTRS, 
Zhejiang, China). LEDs were positioned at plant height for the downward lighting and around the base for the upward lighting; they were lit for $12 \mathrm{~h} /$ day (0900-2100 HR) (Fig. 1). The wavelengths of light sources recorded with a spectrometer (SR9910-v7; Irradiant Ltd., Tranent, UK) were 300 to $800 \mathrm{~nm}$. The temperature of directly lit leaves measured by an infrared thermometer was $<0.5^{\circ} \mathrm{C}$ higher than the air temperature. The plants were fertilized every week with a commercial fertilizer (NPK 6:10:5 diluted 1/1000; Hyponex, Osaka, Japan). The treatments were established with a randomized block design of three blocks with four plants per block. Data were based on three replicate plants distributed over three blocks $(n=3)$. Plants grown for 2 weeks under each treatment condition were measured.

Measurements of chlorophyll fluorescence and gas exchange. Leaves were classified as lower, middle, or upper. In each layer, we measured the maximum potential photochemical efficiency (the ratio of variable to maximum fluorescence, Fv/Fm) using an Imaging-PAM fluorometer (Walz, Effeltrich, Germany) to evaluate the degree of senescence. Leaves were maintained in darkness for $30 \mathrm{~min}$ before measurements were performed (Zhang et al., 2015).

\section{(A) Lighting conditions}

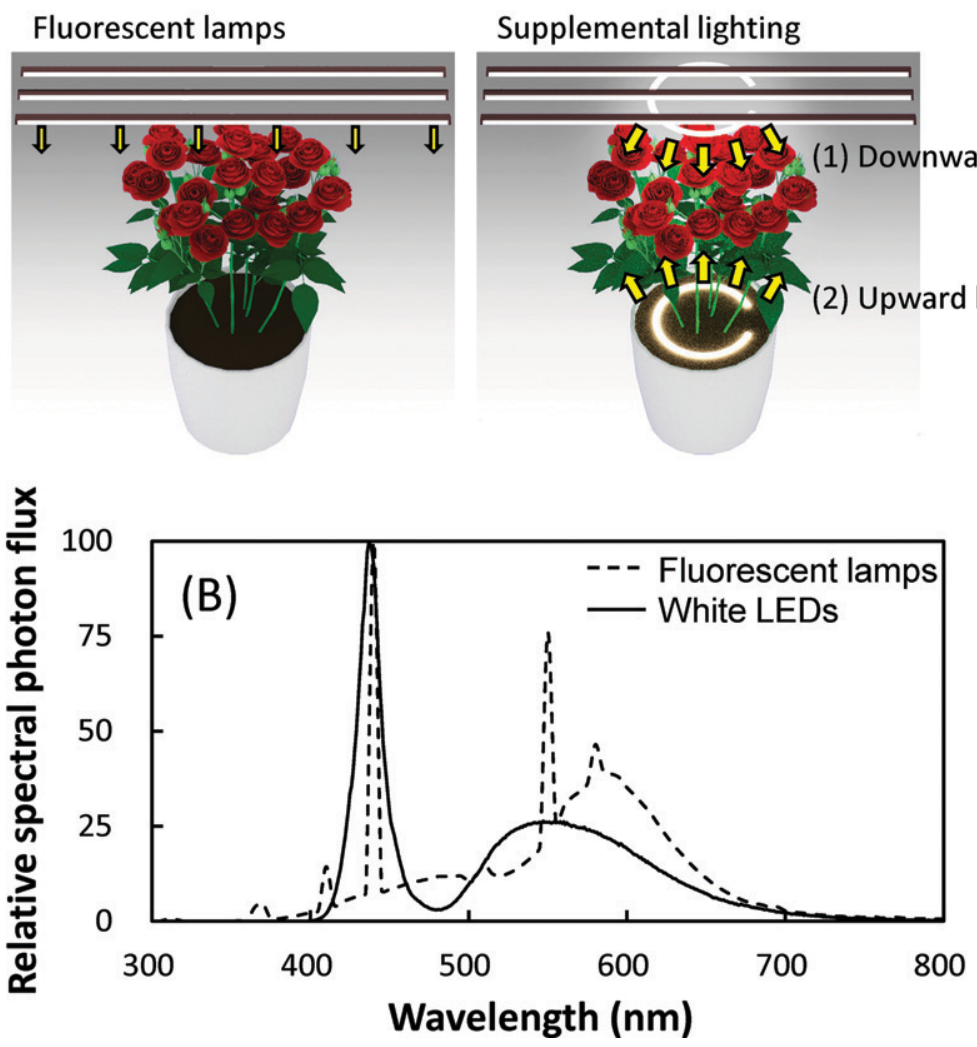

Fig. 1. Schematic diagram of the experimental design of the present study. (A) Lighting conditions and (B) the relative spectral photon flux of supplemental lighting [white light-emitting diodes (LEDs)] and white fluorescent lamp. Miniature roses (Rosa hybrida L.) were grown in 1-L pots in a greenhouse for 2 years until flower buds appeared in March. Before they bloomed, the plants were moved to a laboratory under fluorescent lamps at 10 to $20 \mu \mathrm{mol} \cdot \mathrm{m}^{-2} \cdot \mathrm{s}^{-1}$ for the following 2-week treatments: control (no supplemental lighting); downward lighting at $150 \mu \mathrm{mol} \cdot \mathrm{m}^{-2} \cdot \mathrm{s}^{-1}$; and upward lighting at $150 \mu \mathrm{mol} \cdot \mathrm{m}^{-2} \cdot \mathrm{s}^{-1}$. The supplemental LEDs were set 5 to $10 \mathrm{~cm}$ away from the plants and lit for $12 \mathrm{~h}(0900-2100 \mathrm{HR})$.
After 2 weeks of cultivation, we counted total buds, dead buds, and flowers by eye and calculated the ratios of dead buds, unopened buds, and flowers in each treatment.

Statistical analysis. Data are presented as means \pm SE. An analysis of variance with a post hoc Tukey's test was performed using SPSS statistical software (SPSS, Chicago, IL). Differences were considered significant at $P<0.05$.

\section{Results}

Effects of supplemental lighting on leaf senescence and photosynthetic characteristics. Without supplemental lighting, chlorophyll and rubisco contents were reduced in the middle leaves and were not measurable in the lower leaves, which had senesced (Fig. 2); no difference between treatments was detected in the upper leaves. Contents were significantly higher with upward lighting than with downward lighting in the lower leaves, but not in the middle or upper leaves. Fv/Fm without supplemental lighting was similar to that of other treatments in the upper leaves, decreased in the middle leaves, and not measurable in the lower leaves (Fig. 3). Fv/Fm with downward lighting was significantly lower than that with upward lighting in the lower leaves, but not in the middle or upper leaves. $\mathrm{CO}_{2}$ assimilation rates and $g_{\mathrm{S}}$ in the upper leaves were not significantly different between downward and upward lighting, but they were significantly higher with downward lighting than without supplemental lighting (Fig. 4A and C). Because the upward lighting lit mainly the lower leaves, and because the control had no supplemental lighting, we measured the photosynthetic rates in the lower leaves. The $\mathrm{CO}_{2}$ assimilation rate and $g_{\mathrm{S}}$ in the control were not detectable (Fig. 4B).
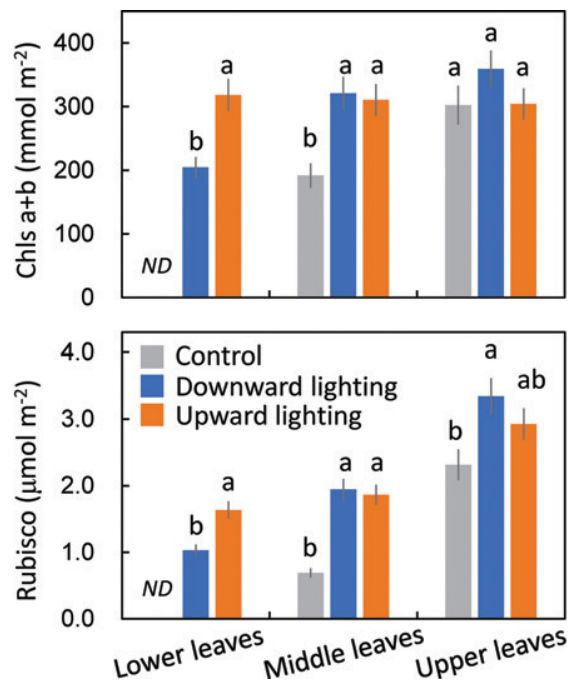

Fig. 2. Effects of supplemental lighting on chlorophyll and rubisco contents in leaves. Plants had no supplemental lighting (control), downward lighting at $150 \mu \mathrm{mol} \cdot \mathrm{m}^{-2} \cdot \mathrm{s}^{-1}$, or upward lighting treatment at $150 \mu \mathrm{mol} \cdot \mathrm{m}^{-2} \cdot \mathrm{s}^{-1}$. The same letter above columns indicates no significant difference among treatments within a leaf layer $(P<0.05)$ according to the Tukey-Kramer test. 


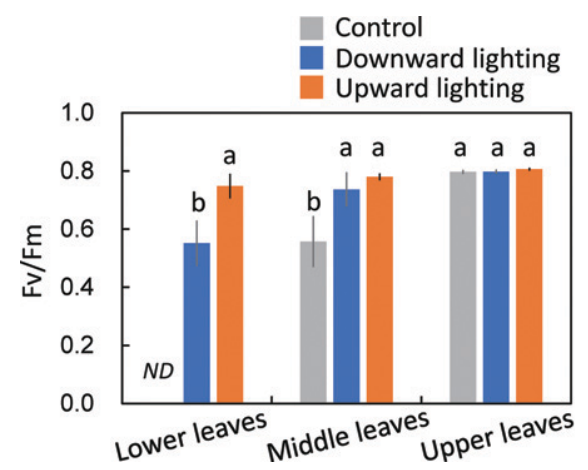

Fig. 3. Effects of supplemental lighting on Fv/Fm. Fv/Fm is the maximum potential photochemical efficiency in leaves. Plants experienced no supplemental lighting (control), downward lighting at $150 \mu \mathrm{mol} \cdot \mathrm{m}^{-2} \cdot \mathrm{s}^{-1}$, or upward lighting at $150 \mu \mathrm{mol} \cdot \mathrm{m}^{-2} \cdot \mathrm{s}^{-1}$. The same letter above columns indicates no significant difference among treatments within a leaf layer $(P<0.05)$ according to the Tukey-Kramer test.

Those in the lower leaves lit by upward lighting at $150 \mu \mathrm{mol} \cdot \mathrm{m}^{-2} \cdot \mathrm{s}^{-1}$ were higher with upward lighting treatment than with downward lighting treatment (Fig. 4B and D).

Effects of supplemental lighting on flower bud formation. Before the 2-week treatment, the number of buds per plant was $55.6 \pm 1.2$, with no significant differences among plants.
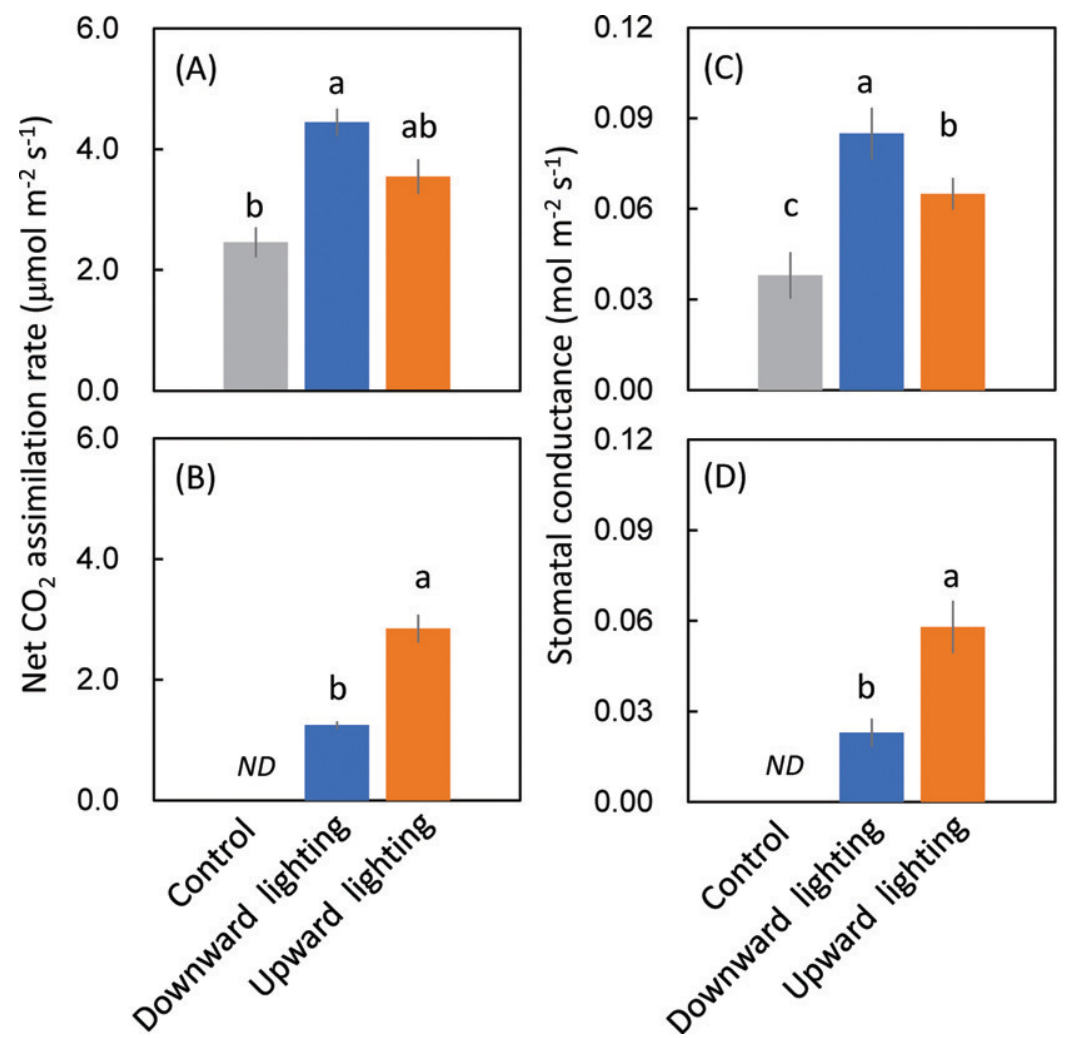

Fig. 4. Effects of supplemental lighting on the photosynthetic rate. Net $\mathrm{CO}_{2}$ assimilation rates in plants grown with no supplemental lighting (control), downward lighting at $150 \mu \mathrm{mol} \cdot \mathrm{m}^{-2} \cdot \mathrm{s}^{-1}$, and upward lighting at $150 \mu \mathrm{mol} \cdot \mathrm{m}^{-2} \cdot \mathrm{s}^{-1}$ analyzed with a portable gas exchange system (LI-6400XT; LICOR Inc., Lincoln, NE) are shown. (A) $\mathrm{CO}_{2}$ assimilation rates and (C) stomatal conductance at $150 \mu \mathrm{mol} \cdot \mathrm{m}^{-2} \cdot \mathrm{s}^{-1}$ downward lighting in upper leaves that underwent each treatment. (B) $\mathrm{CO}_{2}$ assimilation rates and (D) stomatal conductance at $150 \mu \mathrm{mol} \cdot \mathrm{m}^{-2} \cdot \mathrm{s}^{-1}$ upward lighting in lower leaves that underwent each treatment. The same letter above the columns indicates no significant difference among treatments $(P<0.05)$ according to the Tukey-Kramer test. assimilation rates and $g_{\mathrm{S}}$ in upper leaves with downward lighting were not significantly different in plants grown with downward and upward lighting treatments (Fig. 4A and C). Lower leaves that underwent the upward lighting treatment had a significantly higher $\mathrm{CO}_{2}$ assimilation rate and $g_{\mathrm{S}}$ than those that underwent the downward lighting treatment (Fig. 4B and D), which is consistent with the high rubisco content in the lower leaves that underwent upward lighting treatment (Fig. 2). In summary, we showed that 1) without supplemental lighting, leaf senescence was promoted (Figs. 2 and 3) and flower buds browned and died (Fig. 5); 2) supplemental downward lighting promoted flower bud maturation and senescence of lower leaves; and 3) supplemental upward lighting promoted flower bud maturation and retarded senescence specifically in lower leaves. Although more flowers successfully opened with downward lighting than with upward lighting, upward lighting can be another option for indoor rose management because upward lighting does not require extra space for lighting equipment (Fig. 7).

Supplementary light is often applied to ornamental crops to promote the productivity and external quality of cut flowers and potted plants under protected cultivation (Fanourakis et al., 2013). During flower bud opening in roses in our experiment, the light requirement was absolute, and darkness totally inhibited flower bud burst. Light has been reported to have a considerable impact on sugar metabolism during bud burst (Girault et al., 2010). Sugars control the biosynthesis, transport, or signaling of certain hormones, including auxin and cytokinin (Kushwah and Laxmi, 2013; LeClere et al., 2010; Mishra et al., 2009; Sairanen et al., 2012; Stewart Lilley et al., 2012). In addition, sucrose has been identified recently as an early modulator of the key hormonal mechanisms controlling bud outgrowth in rose (Barbier et al., 2015). Because light is indispensable for mobilization of the carbohydrate reserves necessary for bud burst (Girault et al., 2010), the absence of burst of rose buds in darkness could, in part, be explained by the incapacity of the bud to mobilize its own carbohydrate reserves.

Plants respond to various combinations of light colors via their photosynthetic pigments (chlorophylls and carotenoids) and photoreceptor pigments (phytochromes, cryptochromes, and phototropins) (Fukuda et al., 2016). Light wavelength (as well as light intensity and the photoperiod) greatly affects plant growth (Inada, 1976; Lin et al., 2013; McCree, 1971-72). Therefore, understanding the response to light stimuli might lead to the development of new methods to control flower opening and water uptake in indoor plants. The light level during cultivation also affects the regulation of water loss, which is an important factor in postharvest quality (Fanourakis et al., 2019). Therefore, it is necessary to identify the optimal growth conditions for indoor plant management during periods of low light availability. 

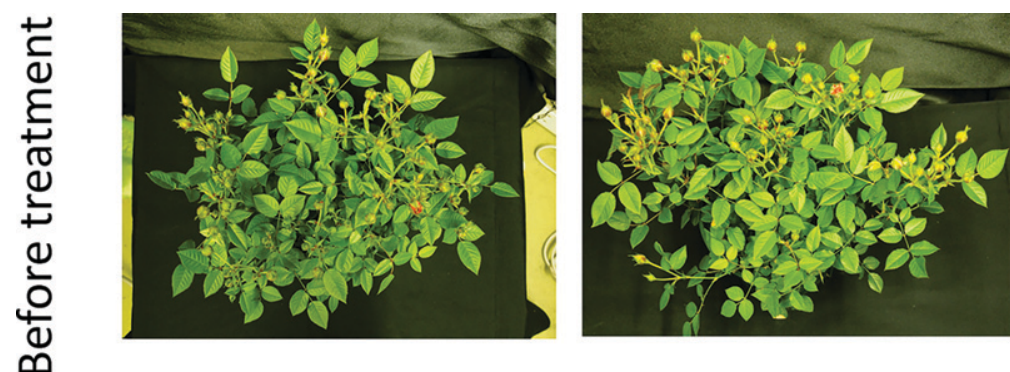

Supplemental upward lighting

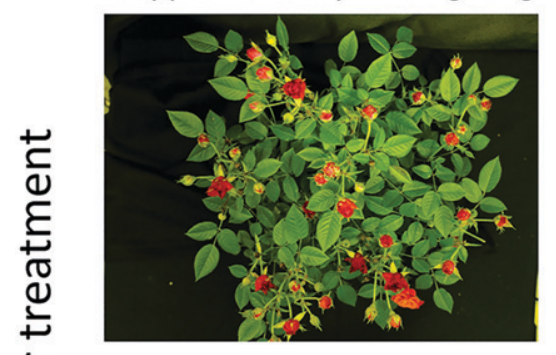

\section{Supplemental downward lighting}

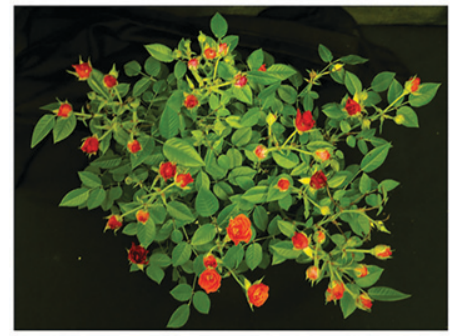

No supplemental lighting

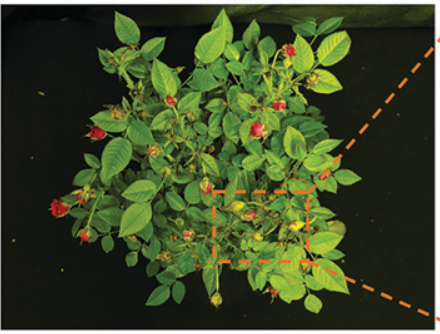

No supplemental lighting (closeup)

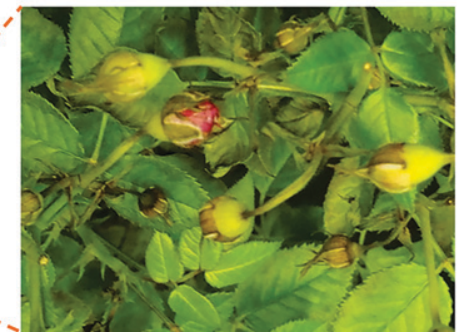

Fig. 5. Effects of supplemental lighting on flower bud maturation. Photographs of flower buds before (day 0 ) and after (day 14) 2-week treatments. Plants experienced no supplemental lighting, supplemental downward lighting at $150 \mu \mathrm{mol} \cdot \mathrm{m}^{-2} \cdot \mathrm{s}^{-1}$, or supplemental upward lighting at $150 \mu \mathrm{mol} \cdot \mathrm{m}^{-2} \cdot \mathrm{s}^{-1}$.

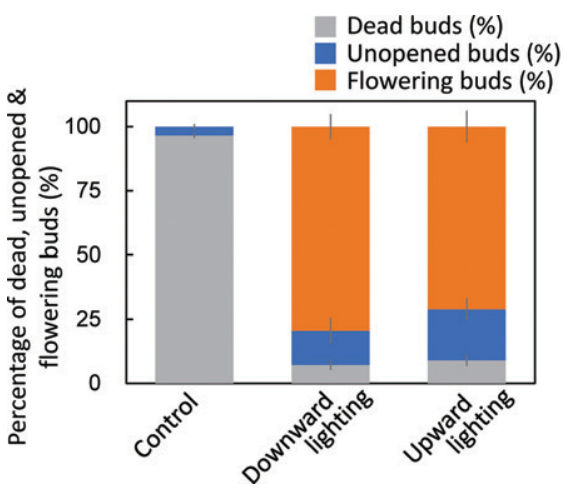

Fig. 6. Effects of supplemental lighting on the fate of flower buds. Ratios of dead buds, unopened buds, and flowering buds of plants with no supplemental lighting, supplemental downward lighting at $150 \mu \mathrm{mol} \cdot \mathrm{m}^{-2} \cdot \mathrm{s}^{-1}$, and supplemental upward lighting at $150 \mu \mathrm{mol} \cdot \mathrm{m}^{-2} \cdot \mathrm{s}^{-1}$ are shown. After 2 weeks of treatment, the numbers of dead, unopened, and flowering buds were counted by eye, and the ratios were calculated for each treatment. Values are mean $\pm \operatorname{SE}(n=3)$.

Supplemental upward lighting can retard leaf senescence of the lower leaves while the photosynthesis rate increases. Because light has been shown to have an effect on pigment accumulation during development, darkness or extremely low light (i.e., $<10-20 \mu \mathrm{mol}$. $\mathrm{m}^{-2} \cdot \mathrm{s}^{-1}$ ) is known to induce senescence, which is accompanied by a rapid breakdown of chlorophyll concomitantly with chloroplast disassembly and a decrease in photosynthesis (Gepstein et al., 2003; Liebsch and Keech, 2016; Lim et al., 2007). The present work clearly showed that upward lighting can suppress the senescence of lower leaves (Fig. 2). This is supported by the recent work that showed that supplemental upward lighting using LEDs could retard outer leaf senescence and increase the photosynthetic rate of lettuce, thus enhancing yield (Joshi et al., 2017; Zhang et al., 2015), and that the postharvest senescence of green vegetables could be delayed by irradiation with low light intensities (such as 20-30 $\mu \mathrm{mol} \cdot \mathrm{m}^{-2} \cdot \mathrm{s}^{-1}$ ) (Büchert et al., 2011; Costa et al., 2013; Favre et al., 2018; GergoffGrozeff et al., 2013).

The leaf senescence process is multifaceted; it involves a complex regulatory network that became apparent through studies demonstrating differential and global gene expression during natural and dark-induced senescence in Arabidopsis thaliana (Buchanan-Wollaston et al., 2005; Gepstein et al., 2003; Sobieszczuk-Nowicka et al., 2018). Light is arguably the most significant environmental factor; it affects not only photosynthesis and photo-
(A) Without supplemental lighting

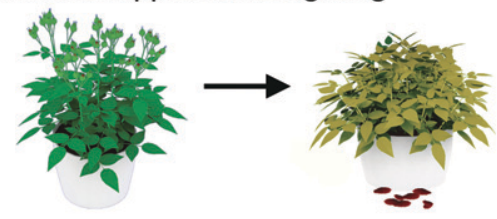

(B) Supplemental downward lighting

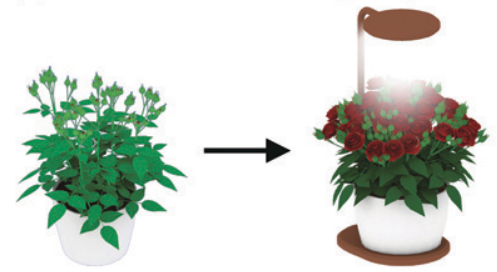

(C) Supplemental upward lighting

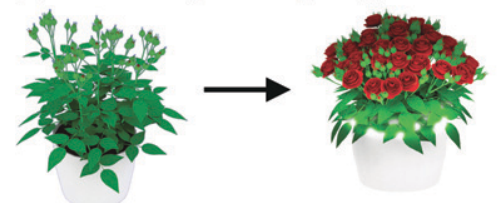

Fig. 7. Supplemental upward lighting had positive effects on indoor rose management. (A) Without supplemental lighting, leaves senesced and flower buds died. (B) Supplemental downward lighting promoted flowering as well as lower leaf senescence. (C) Supplemental upward lighting promoted flowering and retarded lower leaf senescence.

assimilate availability but also phytochromes, which are photoreceptors that signal red and far-red light information. Recent studies have demonstrated that phytochromes are involved as mediators in light signaling-dependent retardation of senescence (Woo et al., 2019) because red light negatively regulates leaf senescence and far-red light positively regulates it (Lim et al., 2018). Moreover, phytochromes are regulators of the genes involved in chloroplast maintenance and chlorophyll catabolism (Liebsch and Keech, 2016). Although it cannot be ruled out that the metabolic status including the sugar level is involved in other signaling pathways for dark-induced or shade-induced senescence, it is highly possible that photoreceptor-mediated light signaling had an important role in retarding leaf senescence when supplemental upward lighting was applied.

Use of supplemental upward lighting during indoor rose management. In modern society, many people spend much of their time under stress and have no time for contact with nature outside their immediate surroundings. Flower arrangements offer a way of bringing nature into daily indoor life. The relaxing effects of fresh flowers such as roses are empirically known. Many studies of the psychological effects of exposure to blooming or green plants have shown that plants alleviate physiological stress and provide more positive feelings and higher satisfaction (Chang and Chen, 2005; Coleman and Mattson, 1995; Ikei et al., 2014; Lohr et al., 1996; Ulrich et al., 1991; Verderber and Reuman, 1987).

Studies have shown that introducing plants and flowers into hospital rooms during 
the recovery period has a positive influence linked directly to health outcomes of surgery patients (Diette et al., 2003; Lohr and PearsonMims, 2000; Park et al., 2004; Park and Mattson, 2009; Ulrich, 1984, 1992). Therefore, blooming or green plants as well as colorful fresh cut flowers in a hospital environment could be a noninvasive, inexpensive, and effective complementary medicine for patients. When properly maintained, ornamental indoor plants can provide a great opportunity for patients denied outdoor scenery, and they can provide meaningful therapeutic contact for patients who spend much of their time indoors while recovering. Upward lighting can help keep plants green and promote flowering, thus improving one's mood.

\section{Literature Cited}

Barbier, F., T. Péron, M. Lecerf, M.D. Perez-Garcia, Q. Barrièr, J. Rolčík, S. Boutet-Mercey, S. Citerne, R. Lemoine, B. Porcheron, H. Roman, N. Leduc, J.L. Gourrierec, J. Bertheloot, and S. Sakr. 2015. Sucrose is an early modulator of the key hormonal mechanisms controlling bud outgrowth in Rosa hybrida. J. Expt. Bot. 66:2569-2582, doi: https://doi.org/10.1093/jxb/erv047.

Brouwer, B., A. Ziolkowska, M. Bagard, O. Keech, and P. Gardeström. 2012. The impact of light intensity on shade-induced leaf senescence. Plant Cell Environ. 35:1084-1098, doi: https:// doi.org/10.1111/j.1365-3040.2011.02474.x.

Buchanan-Wollaston, V., T. Page, E. Harrison, E. Breeze, P.O. Lim, H.G. Nam, J.-F. Lin, S.-H. Wu, J. Swidzinski, K. Ishizaki, and C.J. Leaver. 2005. Comparative transcriptome analysis reveals significant differences in gene expression and signalling pathways between developmental and dark/starvation-induced senescence in Arabidopsis. Plant J. 42:567-585, doi: https://doi. org/10.1111/j.1365-313X.2005.02399.x.

Büchert, A.M., M.E. Gómez-Lobato, N.M. Villarrea, P.M. Civello, and G.A. Martínez. 2011. Effect of visible light treatments on postharvest senescence of broccoli (Brassica oleracea L.). J. Sci. Food Agr. 91:355-361, doi: https://doi. org/10.1002/jsfa.4193.

Chang, C. and P. Chen. 2005. Human response to window views and indoor plants in the workplace. HortScience 40:1354-1359, doi: https:// doi.org/10.21273/HORTSCI.40.5.1354.

Coleman, C.K. and R.H. Mattson. 1995. Influences of foliage plants of human stress during thermal biofeedback training. HortTechnology 5:137140, doi: https://doi.org/10.21273/HORTTECH. 5.2.137.

Corbesier, L., P. Lejeune, and G. Bernier. 1998. The role of carbohydrates in the induction of flowering in Arabidopsis thaliana: Comparison between the wild type and a starchless mutant. Planta 206:131-137, doi: https://doi.org/10.1007/ s004250050383.

Costa, L., Y. Montano, C. Carrión, N. Rolny, and J.J. Guiamet. 2013. Application of low intensity light pulses to delay postharvest senescence of $\mathrm{OCi}$ mum basilicum leaves. Postharvest Biol. Technol. 86:181-191, doi: https://doi.org/10.1016/j. postharvbio.2013.06.017.

Currey, J. and R.G. Lopez. 2013. Cutting of Impatient, Pelargonium and Petunia propagated under light-emitting diodes and high-pressure sodium lamp have comparable growth, morphology, gas exchange and post-transplant performance. HortScience 48:428-434, doi: https://doi.org/ 10.21273/HORTSCI.48.4.428.
Diette, G., E. Haponik, and H. Rubin. 2003. Distraction therapy with nature sights and sounds reduces pain during flexible bronchoscopy. Chest 123:941-948, doi: https://doi.org/10.1378/chest. 123.3.941.

Fanourakis, D., R. Pieruschka, A. Savvides, A.J. Macnish, V. Sarlikioti, and E.J. Woltering. 2013. Sources of vase life variation in cut roses: A review. Postharvest Biol. Technol. 78:1-15, doi: https://doi.org/10.1016/j.postharvbio.2012.12.001.

Fanourakis, D., B. Hyldgaard, H. Giday, I. Aulik, D. Bouranis, O. Körner, and C. Ottosen. 2019. Stomatal anatomy and closing ability is affected by supplementary light intensity in rose (Rosa hybrida L.). Hort. Sci. 46:81-89, doi: https://doi.org/10.17221/144/2017-HORTSCI.

Favre, N., A. Bárcena, J.V. Bahima, G. Martínez, and L. Costa. 2018. Pulses of low intensity light as promising technology to delay postharvest senescence of broccoli. Postharvest Biol. Technol. 142:107-114, doi: https://doi. org/10.1016/j.postharvbio.2017.11.006.

Fukuda, N., C. Ajima, T. Yukawa, and J.E. Olsen. 2016. Antagonistic action of blue and red light on shoot elongation in petunia depends on gibberellin, but the effects on flowering are not generally linked to gibberellin. Environ. Exp. Bot. 121:102-111, doi: https://doi.org/10.1016/ j.envexpbot.2015.06.014.

Gan, S. and R.M. Amasino. 1997. Making sense of senescence (molecular genetic regulation and manipulation of leaf senescence). Plant Physiol. 113:313-319, doi: https://doi.org/10.1104/pp.113. 2.313 .

Gergoff-Grozeff, G., A. Chaves, and C. Bartoli. 2013. Low irradiance pulses improve postharvest quality of spinach leaves (Spinacia oleraceae L. Cv Bison). Postharvest Biol. Technol. 77:35-42, doi: https://doi.org/10.1016/j.postharvbio.2012.10.012.

Gepstein, S., G. Sabehi, M.-J. Carp, T. Hajouj, M. Falah, O. Nesher, I. Yariv, C. Dor, and M. Bassani. 2003. Large-scale identification of leaf senescenceassociated genes. Plant J. 36:629-642, doi: https:// doi.org/10.1046/j.1365-313x.2003.01908.x.

Girault, T., F. Abidi, M. Sigogne, S. Pelleschi-Travier, R. Boumaza, S. Sakr, and N. Leduc. 2010. Sugars are under light control during bud burst in Rosa sp. Plant Cell Environ. 33:1339-1350, doi: https:// doi.org/10.1111/j.1365-3040.2010.02152.x.

Goto, E. 2012. Plant production in a closed plant factory with artificial lighting. Acta Hort. 956: 37-49, doi: https://doi.org/10.17660/ActaHortic. 2012.956.2.

Hernández, R. and C. Kubota. 2012. Tomato seedling growth and morphological responses to supplemental LED lighting red:blue ratios under varied daily solar light integrals. Acta Hort. 956:187-194, doi: https://doi.org/10.17660/Acta Hortic.2012.956.19.

Ichimura, K., Y. Kawabata, M. Kishimoto, R. Goto, and K. Yamada. 2003. Shortage of soluble carbohydrates is largely responsible for short vase life of cut 'Sonia' rose flowers. J. Jpn. Soc. Hort. Sci. 72:292-298, doi: https:// doi.org/10.2503/jjshs.72.292.

Ikei, H., M. Komatsu, C. Song, E. Himoro, and Y. Miyazaki. 2014. The physiological and psychological relaxing effects of viewing rose flowers in office workers. J. Physiol. Anthropol. 33:6, doi: https://doi.org/10.1186/1880-6805-33-6.

Inada, K. 1976. Action spectra for photosynthesis in higher plants. Plant Cell Physiol. 17:355-365, doi: https://doi.org/10.1093/oxfordjournals.pcp. a075288.

Joshi, J., G. Zhang, S. Shen, K. Supaibulwatana, C.K.A. Watanabe, and W. Yamori. 2017. A combination of downward lighting and supplemental upward lighting improves plant growth in a closed plant factory with artificial lighting. HortScience 52:831-835, doi: https://doi.org/ 10.21273/HORTSCI1 1822-17.

Kaihara, S. and A. Takimoto. 1980. Studies on the light controlling the time of flower-opening in Pharbitis nil. Plant Cell Physiol. 21:21-26, doi: https://doi.org/10.1093/oxfordjournals.pcp.a0 75985.

Kaihara, S. and A. Takimoto. 1981. Effects of light and temperature on flower-opening in Pharbitis nil. Plant Cell Physiol. 22:215-221, doi: https:// doi.org/10.1093/oxfordjournals.pcp.a076158.

King, R.W., T. Hisamatsu, E.E. Goldschmidt, and C. Blundell. 2008. The nature of floral signals in Arabidopsis. I. Photosynthesis and a far-red photoresponse independently regulate flowering by increasing expression of FLOWERING LOCUS T (FT). J. Expt. Bot. 59:3811-3820, doi: https://doi.org/10.1093/jxb/ern231.

Kushwah, S. and A. Laxmi. 2013. The interaction between glucose and cytokinin signal transduction pathway in Arabidopsis thaliana. Plant Cell Environ. 37:235-253, doi: https://doi.org/ 10.1111/pce.12149.

LeClere, S., E.A. Schmelz, and P.S. Chourey. 2010. Sugar levels regulate tryptophan-dependent auxin biosynthesis in developing maize kernels. Plant Physiol. 153:306-318, doi: https://doi.org/ 10.1104/pp.110.155226.

Liebsch, D. and O. Keech. 2016. Dark-induced leaf senescence: New insights into a complex light-dependent regulatory pathway. New Phytol. 212:563-570, doi: https://doi.org/10.1111/ nph.14217.

Lim, P.O., H.J. Kim, and H.G. Nam. 2007. Leaf senescence. Annu. Rev. Plant Biol. 58:115-136, doi: https://doi.org/10.1146/annurev.arplant.57. 032905.105316.

Lim, J., J.-H. Park, S. Jung, D. Hwang, H.G. Nam, and S. Hong. 2018. Antagonistic roles of phyA and phyB in far-red light-dependent leaf senescence in Arabidopsis thaliana. Plant Cell Physiol. 59:1753-1764, doi: https://doi.org/10.1093/ pcp/pcy153.

Lin, K.H., M.Y. Huang, W.D. Huang, M.H. Hsu, Z.W. Yang, and C.M. Yang. 2013. The effects of red, blue, and white light-emitting diodes on the growth, development, and edible quality of hydroponically grown lettuce (Lactuca sativa L. var. capitata). Scientia Hort. 150:86-91, doi: https://doi.org/10.1016/j.scienta.2012.10.002.

Lohr, V.I. and C.H. Pearson-Mims. 2000. Physical discomfort may be reduced in the presence of interior plants. HortTechnology 10:53-58, doi: https://doi.org/10.21273/HORTTECH.10.1.53.

Lohr, V.I., C.H. Pearson-Mims, and G.K. Goodwin. 1996. Interior plant may improve worker productivity and reduce stress in a windowless environment. J. Environ. Hort. 14:97-100, doi: https://doi.org/10.24266/0738-2898-14.2.97.

McCree, K.J. 1971-72. The action spectrum, absorptance and quantum yield of photosynthesis in crop plants. Agr. Meteorol. 9:191-216, doi: https://doi.org/10.1016/0002-1571(71)90022-7.

Mishra, B.S., M. Singh, P. Aggrawal, and A. Laxmi. 2009. Glucose and auxin signaling interaction in controlling Arabidopsis thaliana seedlings root growth and development. PLoS One 4:e4502, doi: https://doi.org/10.1371/journal.pone.0004502.

Miyazaki, Y., B.J. Park, and J. Lee. 2011. Nature therapy, p. 407-412. In: M. Osaki, A. Braimoh and K. Nakagami (eds.). Designing our future: local perspectives on bioproduction, ecosystems and humanity. United Nations University Press, Tokyo, Japan.

Mortensen, L.M. and T. Fjeld. 1998. Effects of air humidity, lighting period and lamp type on growth and vase life of roses. Scientia Hort. 
73:229-237, doi: https://doi.org/10.1016/S03044238(98)00075-2.

Park, S.H. and R.H. Mattson. 2009. Ornamental indoor plants in hospital rooms enhanced health outcomes of patients recovering from surgery. J. Alt. Complem. Med. 15:975-980, doi: https://doi.org/10.1089/acm.2009.0075.

Park, S., R.H. Mattson, and E. Kim. 2004. Pain tolerance effects of ornamental plants in a simulated hospital patient room. Acta Hort. 639:241-247, doi: https://doi.org/10.17660/ActaHortic.2004. 639.31.

Park, B.J., Y. Tsunetsugu, H. Ishii, S. Furuhashi, H. Hirano, T. Kagawa, and Y. Miyazaki. 2008. Physiological effects of Shinrin-yoku (taking in the atmosphere of the forest) in a mixed forest in Shinano Town, Japan. Scand. J. For. Res. 23:278-283, doi: https://doi.org/10.1080/0282 7580802055978

Paulin, A. 1979. Évolution des glucides dans les divers organes de la rose coupée (var. Carina) alimentée temporairement avec une solution glucose (in French text with English summary). Physiol. Veg. 17:129-143.

Porra, R.J., W.A. Thompson, and P.E. Kriedemann. 1989. Determination of accurate extinction coefficients and simultaneous equations for assaying chlorophylls a and b extracted with four different solvents: Verification of the concentration of chlorophyll standards by atomic absorption spectrometry. Biochim. Biophys. Acta 975:384-394, doi: https://doi.org/10.1016/ S0005-2728(89)80347-0

Sabzalian, M.R., P. Heydarizadeh, M. Zahedi, A. Boroomand, M. Agharokh, M.R. Sahba, and B. Schoefs. 2014. High performance of vegetables, flowers, and medicinal plants in a red-blue LED incubator for indoor plant production. Agron. Sustain. Dev. 34:879-886, doi: https:// doi.org/10.1007/s13593-014-0209-6.

Sairanen, I., O. Novák, A. Pěnčík, Y. Ikeda, B. Jones, G. Sandberg, and K. Ljung. 2012. Soluble carbohydrates regulate auxin biosynthesis via PIF proteins in Arabidopsis. Plant Cell 24:4907-4916, doi: https://doi.org/10.1105/tpc. 112.104794 .

Sheldon, C.C., E.J. Finnegan, D.T. Rouse, M. Tadege, D.J. Bagnall, C.A. Helliwell, W.J.
Peacock, and E.S. Dennis. 2000. The control of flowering by vernalization. Curr. Opin. Plant Biol. 3:418-422, doi: https://doi.org/10.1016/ s1369-5266(00)00106-0.

Stewart Lilley, J.L., C.W. Gee, I. Sairanen, K. Ljung, and J.L. Nemhauser. 2012. An endogenous carbon-sensing pathway triggers increased auxin flux and hypocotyl elongation. Plant Physiol. 160:2261-2270, doi: https://doi.org/ 10.1104/pp.112.205575.

Sobieszczuk-Nowicka, E., T. Wrzesiński, A. Bagniewska-Zadworna, S. Kubala, R. RucińskaSobkowiak, W. Polcyn, L. Misztal, and A.K. Mattoo. 2018. Physio-genetic dissection of dark-induced leaf senescence and timing its reversal in barley. Plant Physiol. 178:654-671, doi: https://doi.org/10.1104/pp.18.00516.

Ulrich, R.S. 1984. View through a window may influence recovery from surgery. Science $224: 420$ 421, doi: https://doi.org/10.1126/science.6143402.

Ulrich, R.S. 1992. How design impacts wellness. Healthc. Forum J. 35:20-25.

Ulrich, R.S., R.F. Simons, B.D. Losito, E. Fiorito, M.A. Miles, and M. Zelson. 1991. Stress recovery during exposure to natural and urban environments. J. Environ. Psychol. 11:201230, doi: https://doi.org/10.1016/S0272-4944 (05)80184-7.

van Doorn, W.G. and E.J. Woltering. 2008. Physiology and molecular biology of petal senescence. J. Expt. Bot. 59:453-480, doi: https:// doi.org/10.1093/jxb/erm356.

Verderber, S. and D. Reuman. 1987. Windows, views, and health status in hospital therapeutic environments. J. Archit. Plann. Res. 4:120-133.

Weaver, L.M. and R.M. Amasino. 2001. Senescence is induced in individually darkened Arabidopsis leaves, but inhibited in whole darkened plants. Plant Physiol. 127:876-886, doi: https://doi.org/ 10.1104/pp.010312.

Woo, H.R., H.J. Kim, P.O. Lim, and H.G. Nam 2019. Leaf senescence: Systems and dynamics aspects. Annu. Rev. Plant Biol. 70:347-376, doi: https://doi.org/10.1146/annurev-arplant-050718095859.

Yamori, W. and T. Shikanai. 2016. Physiological functions of cyclic electron transport around photosystem I in sustaining photosynthesis and plant growth. Annu. Rev. Plant Biol. 67:81-106, doi: https://doi.org/10.1146/annurev-arplant-04 3015-112002.

Yamori, W., K. Noguchi, and I. Terashima. 2005. Temperature acclimation of photosynthesis in spinach leaves: Analyses of photosynthetic components and temperature dependencies of photosynthetic partial reactions. Plant Cell Environ. 28:536-547, doi: https://doi.org/10.1111/ j.1365-3040.2004.01299.x.

Yamori, W., K. Noguchi, K. Hikosaka, and I. Terashima. 2009. Cold-tolerant crop species have greater temperature homeostasis of leaf respiration and photosynthesis than cold-sensitive species. Plant Cell Physiol. 50:203-215, doi: https://doi.org/10.1093/pcp/pcn189.

Yamori, W., K. Noguchi, K. Hikosaka, and I. Terashima. 2010. Phenotypic plasticity in photosynthetic temperature acclimation among crop species with different cold tolerances. Plant Physiol. 152:388-399, doi: https://doi.org/10.1104/ pp.109.145862.

Yamori, W., A. Makino, and T. Shikanai. 2016a. A physiological role of cyclic electron transport around photosystem I in sustaining photosynthesis under fluctuating light in rice. Sci. Rep. 6:20147, doi: https://doi.org/10.1038/srep20147.

Yamori, W., E. Kondo, D. Sugiura, I. Terashima, Y. Suzuki, and A. Makino. 2016b. Enhanced leaf photosynthesis as a target to increase grain yield: Insights from transgenic rice lines with variable Rieske FeS protein content in the Cytochrome b6/f complex. Plant Cell Environ. 39:80-87, doi: https://doi.org/10.1111/pce.12594.

Zhang, H.H., Q. Yang, and H.J. Yang. 2011. Selfadaptive and precise supplementary lighting system for plant with controllable LED intensity (in Chinese text with English summary). J. Trans. CSAE 27:153-158, doi: https://doi.org/ 10.3969/j.issn.1002-6819.2011.09.027.

Zhang, G., S. Shen, M. Takagaki, T. Kozai, and W. Yamori. 2015. Supplemental upward lighting from underneath to obtain higher marketable lettuce (Lactuca sativa) leaf fresh weight by retarding senescence of outer leaves. Front. Plant Sci. 6:1110, doi: https://doi.org/10.3389/ fpls.2015.01110 

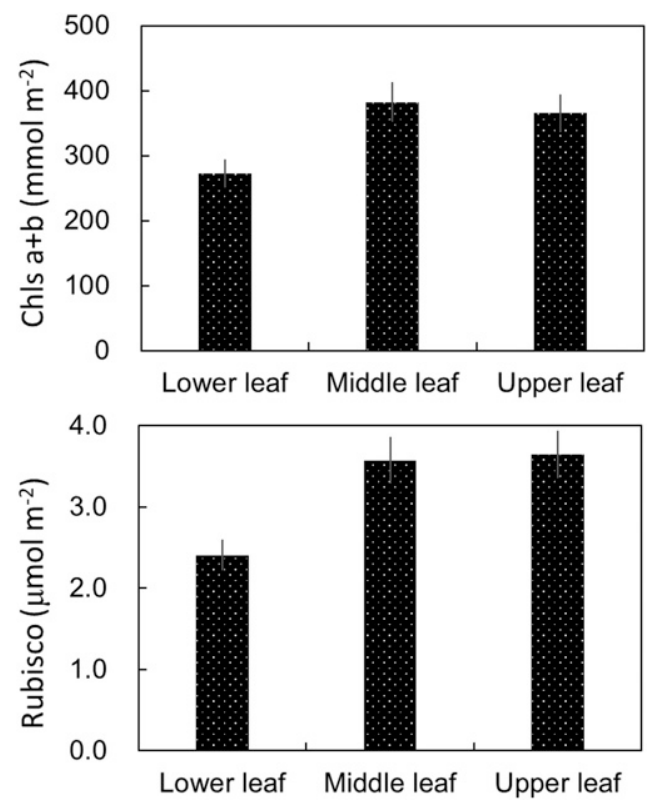

Supplemental Fig. 1. Chlorophyll and Rubisco contents before treatments Chlorophyll and Rubisco contents in lower, middle, and upper leaves were quantified before the 2-week supplemental lighting treatments. 